\title{
THE ROLE OF THE FERTILIZED EGG: REACTIONS IN THE GUINEA-PIG UTERUS AT OVO- IMPLANTATION AND AFTER THREAD TRAUMATIZATION
}

\author{
R. DEANESLY \\ A.R.C. Institute of Animal Physiology, \\ Babraham, Cambridge
}

(Received 23rd October 1966)

\begin{abstract}
Summary. Unilaterally sterilized guinea-pigs were mated and the sterile uterine horn traumatized 0 to 7 days later by the passage of two or more threads which were left in situ. The animals were killed 3 to 7 days after traumatization and the endometrial reactions studied histologically. Although deciduomata developed in uteri traumatized 4 to 7 days after mating, those traumatized up to 3 days after mating and killed up to 5 days later showed little reaction and contrasted markedly with the corresponding horns in which fertilized eggs were becoming implanted. This difference, not affected by exogenous progesterone treatment, indicates that the fertilized eggs have a specific capacity to induce changes in the endometrium, while it is non-reactive to other stimuli.

Traumatization of both uterine horns did not completely inhibit ovoimplantation or subsequent pregnancy.
\end{abstract}

\section{INTRODUCTION}

The object of the present work was to make a histological comparison between the changes in the uterine endometrium associated with ovo-implantation in the guinea-pig and those induced by trauma (such as would stimulate deciduomata) under the same hormonal conditions. Such a comparison should throw light on implantation processes and, in particular, on the role of the fertilized egg.

A preliminary note was published on this work (Deanesly, 1964).

\section{MATERIALS AND METHODS}

The guinea-pigs were from the colony maintained at the A.R.C. Institute of Animal Physiology. The morning on which the vaginal plug was found was designated Day 0, (the day of mating), and subsequent Days 1, 2, etc., post coitum (p.c.). Operations were carried out under ether anaesthesia; one uterine horn was sterilized by removal either of the left ovary or of a piece of the left Fallopian tube. The uterus on the sterile side was traumatized by the passage across the lumen of two or more threads (Arbrasilk No. 2) which were 
left in position. At autopsy, the uterus was fixed in Bouin's fluid and after fixation the threads were removed. When a comparison was made between the effects on the uterus of the passage of threads and of similar threads left in situ, the decidual reaction was histologically similar but greater in the latter case. In two experiments, in which traumatization was by a sharp scalpel instead of by threads, the reaction of the endometrium was more pronounced.

Serial sections were cut at $7 \mu$ through the traumatized region and through more than twenty early implantation sites, up to Day 8 p.c., in the other uterine horns or in normal females. Staining was in haematoxylin and eosin. In the guinea-pig, ovo-implantation takes place $6 \frac{1}{2}$ to 7 days after mating (Sansom \& Hill, 1931) and implantation sites can be seen as swellings at about $9 \frac{1}{2}$ days p.c. Many animals were injected with Pontamine blue in attempts to locate early implantation sites, but well-defined blue areas were rarely seen; the best occurred $6 \frac{1}{2}$ to 7 days after mating. Owing to the amount of work involved, the right horn was not in all cases sectioned serially for early implantation sites. The process of deciduoma development was similar in mated nonpregnant and unmated females. Progesterone tablets, placed subcutaneously in three animals, were removed at autopsy, dried and re-weighed so that the amounts absorbed could be determined.

\section{RESULTS}

\section{The effects of traumatization on the uterine endometrium}

Traumatization on Days $0,1,2$ or 3 p.c. Table 1 summarizes decidual reactions in the thirty-nine experimental animals traumatized 1 to 6 days after mating. Where sections through the traumatized uterus near the point of entry of the thread show no reaction or only a diffuse proliferation of stromal cells, the deciduoma is recorded as absent. The other uteri are divided into those showing early decidual development and those with a differentiated deciduoma which has spread over a large area of the section.

Four unilaterally ovariectomized females had threads placed through the sterilized uterine horns 1 day after mating and were killed 5, 6 and 7 days later. In two of these animals, sections showed implantation sites with extensive decidualization in the pregnant horn, but in the traumatized horns there was no decidual response (Pl. 1, Figs. 3 and 4). A similar striking difference be-

\section{EXPLANATION OF PLATE 1}

Sections through early implantation sites of the guinea-pig and corresponding sterile horn. $\times 60$.

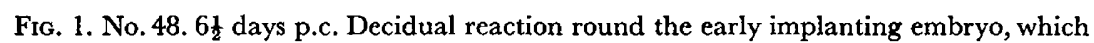
has just passed through the epithelium.

FIG. 2. No. 2. 7 days p.c. A slightly later embryo round which there has been a further development of decidual tissue, including the maternal symplasma with small nuclei (Sansom \& Hill, 1931).

Frg. 3. No. 61.8 days p.c. In the tube-shaped embryo the amnio-embryonal mass lies at the closed end, projecting into the decidual cavity, which is surrounded by differentiated decidual tissue spreading widely into the endometrium.

Fig. 4. No. 61. 8 days p.c. Sterile horn, from the same animal as Fig. 3, 6 days after traumatization, showing a generalized increase in the stromal cells, but no decidual reaction. 
PLATE 1

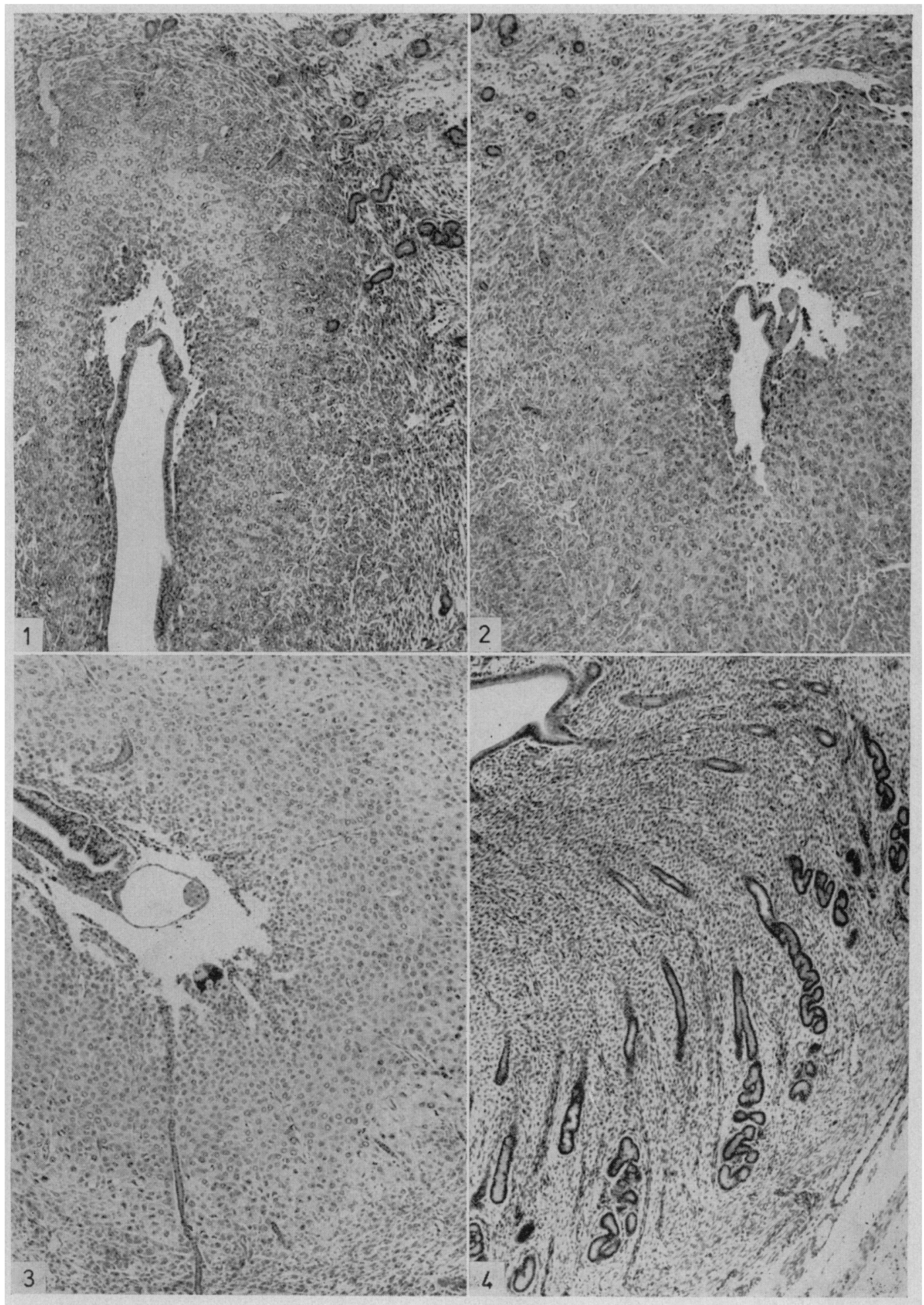

(Facing p. 244) 
PLATE 2

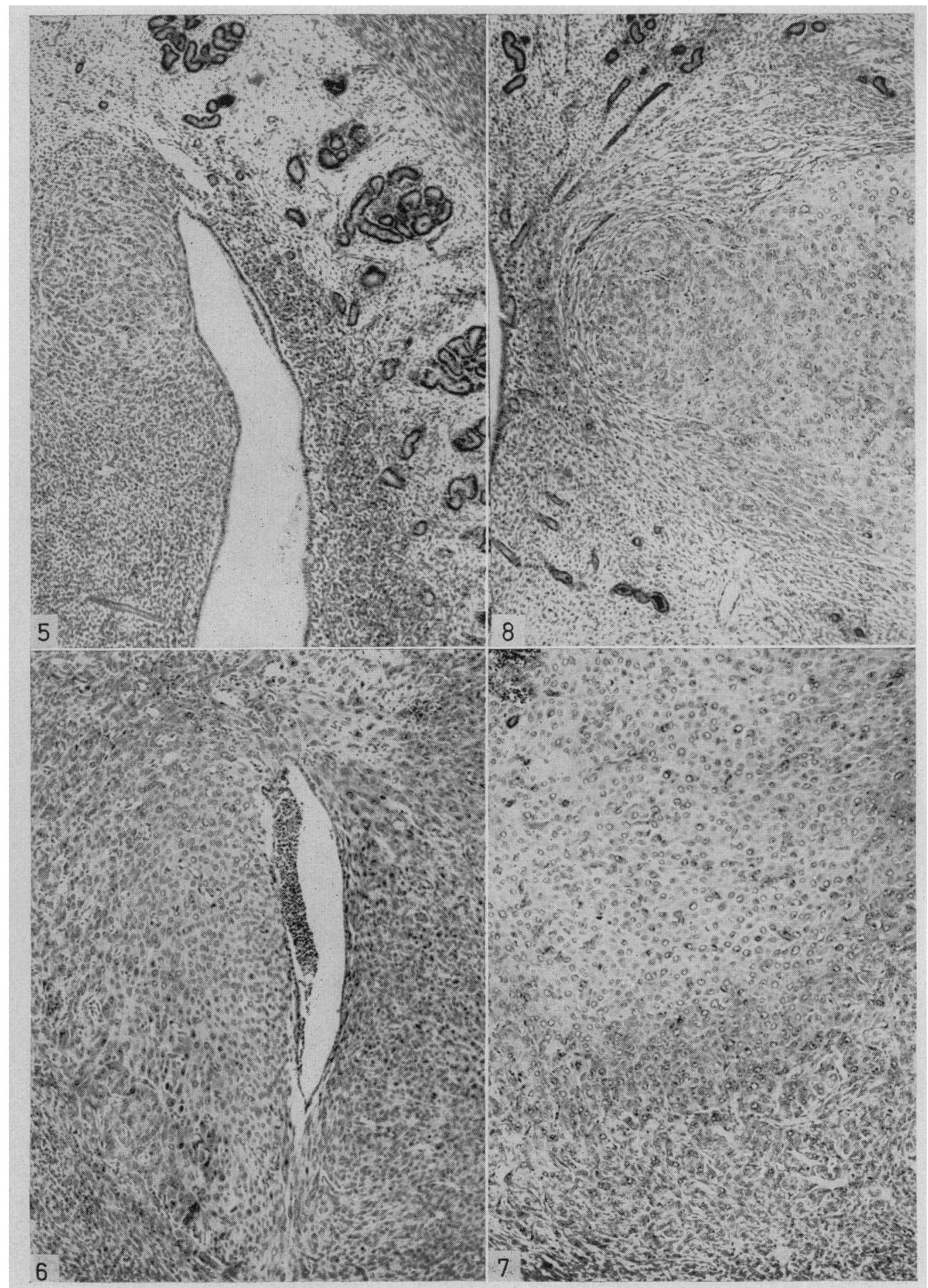

(Facing p. 245) 
tween the pregnant and the sterile traumatized horns was seen in six females traumatized on Day 2 p.c. and killed 5 and 6 days later. It might be suggested that the absence of the ovary could cause a local progesterone deficiency in the corresponding uterine horn. In the present experiments, however, there is no evidence of this; six of the females traumatized on Days 1 or 2 still had both ovaries, only the left Fallopian tubes having been severed. Nevertheless, it was not until 8 days p.c., 6 days after traumatization, that the earliest stages of deciduoma formation were distinguishable in some sterile horns (PI. 2, Fig. 5). The fertilized eggs normally reach the uterus at about 3 days p.c. (Squier, 1932) and by this time the uterus is becoming more reactive; of the six experimental animals, two showed early stages of deciduoma differentiation after $4 \frac{1}{2}$ and

\section{TABLE 1}

DEGIDUAL REAGTIONS IN TRAUMATIZED UTERI

\begin{tabular}{c|c|c|c|c|c|c}
\hline $\begin{array}{c}\text { Days p.c. } \\
\text { traumatized }\end{array}$ & $\begin{array}{c}\text { Days } \\
\text { till } \\
\text { autopsy }\end{array}$ & $\begin{array}{c}\text { No. of } \\
\text { animals }\end{array}$ & $\begin{array}{c}\text { No. } \\
\text { pregnant }\end{array}$ & \multicolumn{2}{|c|}{ Differentiated deciduomata } \\
\cline { 4 - 6 } & None & Early & $\begin{array}{c}\text { Diferenti- } \\
\text { ated }\end{array}$ \\
\hline 1 & $5,6,7$ & 4 & 2 & 4 & - & - \\
2 & 4,5 & 2 & 2 & 2 & - & - \\
3 & 6 & 4 & 4 & 2 & 2 & - \\
4 & 32,5 & 4 & 2 & 2 & 2 & - \\
4 & 3 & 2 & - & - & - & 2 \\
& 4 & 2 & - & 1 & 1 & - \\
5 & 5,6 & 2 & 2 & - & - & 2 \\
6 & 3 & 2 & 1 & - & 1 & 1 \\
6 & $2-7$ & 7 & 4 & - & - & 7 \\
& $2,4,5$ & 4 & -2 & - & - & - \\
\hline
\end{tabular}

5 days, and two had well-developed deciduomata 5 and 7 days after traumatization. Only the female in which the uterus was traumatized with a sharp scalpel showed a full reaction 5 days later.

As a further test of whether the absence or delay in the development of the reaction in the sterile horn at this stage was associated with the progesterone requirements of the deciduoma, which are greater than those of ovo-implanta-

\section{EXPLANATION OF PLATE 2}

Stages in the formation of the traumatic deciduoma in the sterile horn of the guinea-pig. $\times 60$.

FIG. 5. No. 98. 8 days p.c., 2 days after traumatization. A small localized deciduoma can be distinguished, top left.

Fig. 6. No. 96.7 days p.c., 4 days after traumatization. Abundant decidual cells can be seen near the point of entry of the thread.

Fig. 7. No. 79.8 days p.c., 4 days after traumatization. Compared to Fig. 6 the deciduoma is more differentiated, with larger cells. It contrasts with Fig. 4, an 8-day uterus traumatized on Day 2 when it was non-reactive, and examined 6 days later.

Fig. 8. No. 16. 9 days p.c. A well-developed, localized deciduoma, 5 days after traumatization. 
tion in the guinea-pig (Deanesly, 1961), six more females, not in Table 1, were traumatized on the day of mating (Day 0), or 1 or 2 days later, and killed after 5 to 7 days at 6,7 and 9 days p.c. Three were injected with $5 \mathrm{mg}$ progesterone in oil on the day of mating or 1 day later, at traumatization. The others had progesterone tablets totalling 229, 220 and $178 \mathrm{mg}$, respectively, placed subcutaneously also at traumatization; at autopsy 7,7 and $8 \mathrm{mg}$ had been absorbed. These animals, of which at least one was pregnant, had normal corpora lutea, but showed no advance in deciduoma development as compared with similar untreated animals in Table 1. The traumatized uteri were of the type shown in Pl. 1, Fig. 4.

In the twenty females, including those receiving progesterone, traumatized up to Day 3 p.c. and killed on or before Day 8 p.c., only four sterile uterine horns showed early stages of decidual development, contrasting markedly with the extensive decidual reactions around implanting eggs in the corresponding pregnant horns (PI. 1, Figs 1 to 3 ).

Traumatization Days 4 to 6 p.c. In the twenty-three females traumatized 4 to 6 days after mating, differentiation of deciduomata was much more rapid than in the previous group, as can be seen from Table 1. Early differentiation stages were found 7 and 8 days after mating and these were more advanced (Pl. 2, Fig. 6) than the ones similarly classified in the previous group. All of the eleven animals traumatized on Days 5 and 6 and killed 4 to 7 days later had fully differentiated deciduomata and those killed at 2 and 3 days showed intermediate stages.

This increased reactivity of the uterus to trauma agrees with Loeb's findings (Loeb, 1908) and is usually attributed to corpus luteum activity. Some other factor may perhaps be involved since exogenous progesterone has not facilitated a reaction earlier in the luteal phase.

The traumatic deciduoma develops similarly in pregnant and non-pregnant females and in the latter, as found by Dempsey (1939), there is no prolongation of the cycle. An animal of the present series, not in Table 1, was traumatized on Day 7 and killed 7 days later; it had a pro-oestrous uterus and no deciduoma was found. Another animal, unmated, traumatized on Day 6 and killed 10 days later, showed a fresh ovulation, but no deciduoma. On the other hand, a pregnant female traumatized on Day 5 and killed on Day 12 p.c. had a welldeveloped deciduoma (Table 1) and another killed on Day 14 p.c., after traumatization on Day 5, also had a deciduoma which was larger than the pregnancy swellings, but this showed some vacuolation and histological signs of regression.

Traumatization of both uterine horns. In five guinea-pigs threads were placed on both sides on Days 1 or 2 p.c. while the fertilized eggs were still in the Fallopian tubes. Two of these animals had a normal living embryo at 23 and 59 days p.c., with evidence in one of three other implantation sites in the opposite horn. In the others, killed 132, 59 and 44 days after the placings of the threads, the first had given evidence of termination of pregnancy followed by normal cycles and infertile matings, and similar infertile cycles were observed in the other two.

Four females had threads placed on Days 4 to 6 p.c. and were killed at 
14, 16 and 19 days p.c. All showed uterine swellings but only two had definite implantation sites with placental tissue but no embryos. Another, at 19 days, had large areas of degenerating decidual tissue and may also have been pregnant.

In a guinea-pig which mated 8 days after traumatization and was killed at 17 days p.c. an implantation site was found but pregnancy had terminated and a fresh ovulation had occurred.

From these few experiments it may be concluded that, in the guinea-pig, threads placed in both uteri after mating do not inhibit egg implantation and are compatible with normal embryonic development although the majority of the embryos fail to survive. In females which mated after traumatization pregnancy was short lived or absent.

\section{DISCUSSION}

The present experiments on the formation of the traumatic deciduoma are in agreement with those of Loeb (1908), who only obtained optimum development when the stimulation of the uterus, by incisions, was done 4 to 6 days after mating. If the cuts were made 1 or 2 days after mating, no deciduomata were stimulated; not until the 4th day was there a positive response from ten out of twelve females (details are lacking of the duration of these experiments).

At the beginning of this work it appeared that deciduoma stimulation from Day 5 onwards might be having an adverse effect on normal embryonic development in the opposite horn, but further experiments have shown definitely that both the embryo and the traumatic deciduoma can develop normally in the same female or even in the same uterine horn. Threads placed in both uteri did not inhibit implantations; one embryo developed normally till autopsied shortly before term.

The comparison of traumatized and pregnant horns in the same animals, 6 to 8 days after mating, showed a striking difference in the extent of decidualization between the implantation sites and the traumatized areas in the corresponding sterile horns, where the threads had been placed in position up to 3 days after mating. The decidualization in the pregnant horn at the time of implantation and possibly earlier, is evidence of the power of the fertilized eggs to induce changes in the surrounding endometrial tissue when it is still non-reactive, i.e. unable to respond to non-specific stimulation, such as is effective from Day 4 onwards. Additional progesterone, given at the time of traumatization in the first 3 days after mating, did not lead to an increased response in the sterile horns as might have been anticipated.

The nature of the changes induced in the surrounding tissue by the fertilized eggs is being further investigated. A recent paper compares changes in the pregnant and corresponding sterile horns of the rat up to 8 days p.c. (Manning, Meli \& Steinetz, 1966). The authors conclude that there is evidence of enzymic activity which is entirely dependent upon the interaction between the blastocyst and the hormonally conditioned uterus, and not upon hormonal stimulation alone. 


\section{ACKNOWLEDGMENTS}

The author gratefully acknowledges a personal grant from the Medical Research Council.

The photomicrographs are the work of Mr Gallup, A.R.G. Institute of Animal Physiology, Babraham.

\section{REFERENCES}

Deanesly, R. (1961) Deciduoma stimulation in the ovariectomized guinea-pig. F. Endocr. 22, xxx.

Deanesly, R. (1964) Observations on the traumatic deciduoma and ovo-implantation in the guineapig. 5 th int. Congr. Anim. Reprod. Trento, vol. 2, p. 384.

Dempsey, E. W. (1939) The relation of deciduomata to the reproductive cycle in the guinea-pig. (Abstract). Anat. Rec. 70, 119.

LOEB, L. (1908) The production of deciduomata and the relation between the ovaries and the formation of the decidua. F. Am. med. Ass. 50, 1897.

Manning, J. P., Meli, A. \& Steinetz, B. G. (1966) Alkaline phosphatase and $\beta$-glucoronidase activity in the rat uterus during early pregnancy. 7. Endocr. 35, 385.

Sansom, G. S. \& Hill, J. P. (1931) Observations on the structure and mode of implantation of the blastocyst of Cavia. Trans. zool. Soc. Lond. 21, 295.

SQuner, R. R. (1932) The living egg and early stages of its development in the guinea-pig. Contr. Embryol. 137, 225. 